\title{
The Nuclear Energy Knowledge and Validation Center Summary of Activities Conducted in Fiscal Year 2016
}

Hans D. Gougar

September 2016

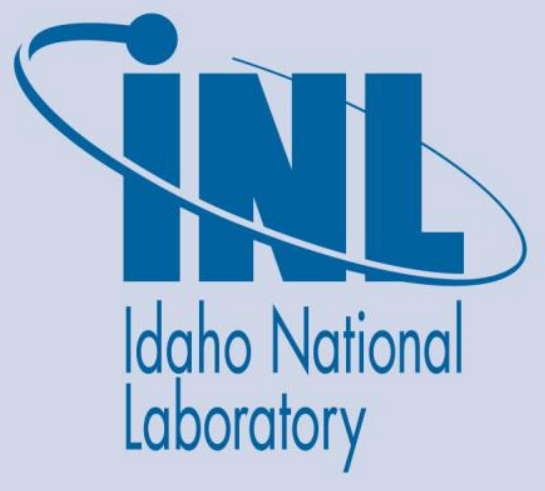

The INL is a U.S. Department of Energy National Laboratory operated by Battelle Energy Alliance 


\section{DISCLAIMER}

This information was prepared as an account of work sponsored by an agency of the U.S. Government. Neither the U.S. Government nor any agency thereof, nor any of their employees, makes any warranty, expressed or implied, or assumes any legal liability or responsibility for the accuracy, completeness, or usefulness, of any information, apparatus, product, or process disclosed, or represents that its use would not infringe privately owned rights. References herein to any specific commercial product, process, or service by trade name, trade mark, manufacturer, or otherwise, does not necessarily constitute or imply its endorsement, recommendation, or favoring by the U.S. Government or any agency thereof. The views and opinions of authors expressed herein do not necessarily state or reflect those of the U.S. Government or any agency thereof. 
INL/EXT-16-40092

Revision 0

\title{
The Nuclear Energy Knowledge and Validation Center Summary of Activities Conducted in Fiscal Year 2016
}

\author{
Hans D. Gougar
}

September 2016

Idaho National Laboratory Idaho Falls, Idaho 83415

http://www.inl.gov

Prepared for the

U.S. Department of Energy

Office of Nuclear Energy

Under DOE Idaho Operations Office

Contract DE-AC07-05ID14517 



\section{The Nuclear Energy Knowledge and Validation Center Summary of Activities Conducted in Fiscal Year 2016}

INL/EXT-16-40092

Revision 0

September 2016
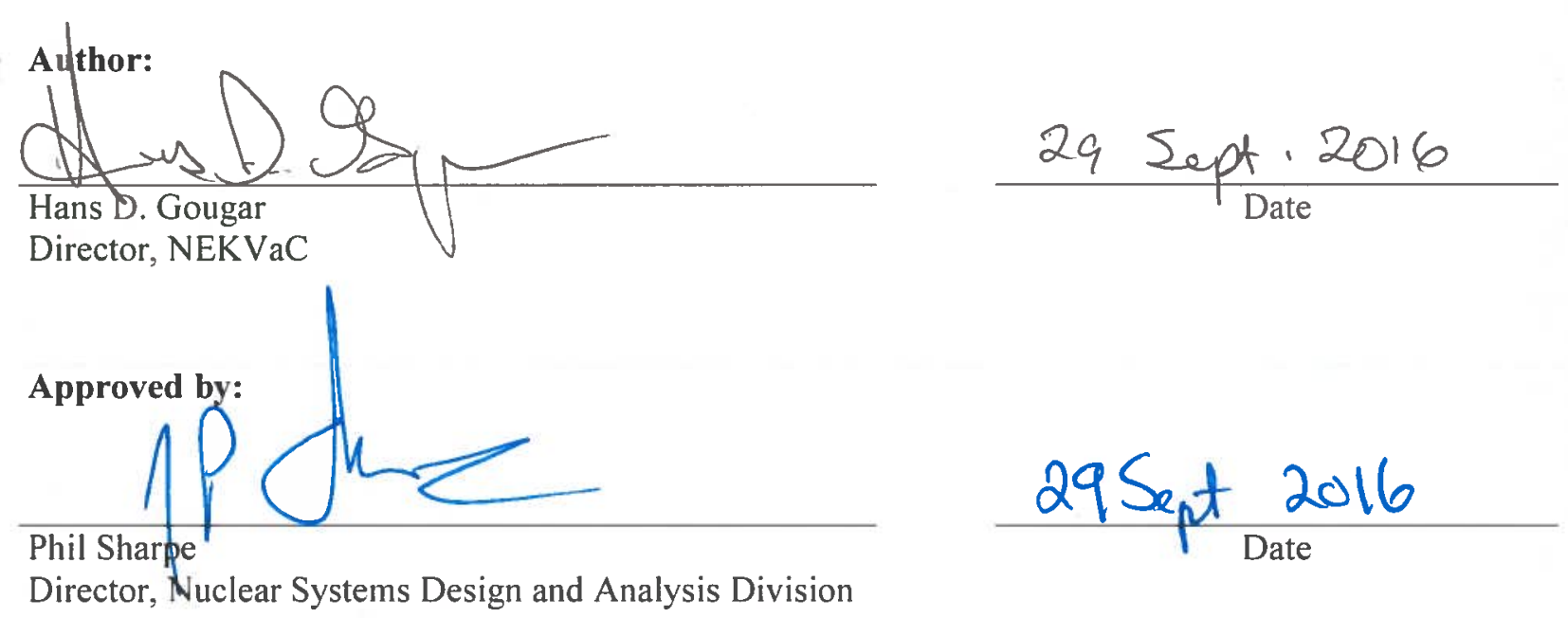



\begin{abstract}
The Nuclear Energy Knowledge and Validation Center (NEKVaC) was initiated in fiscal year (FY) 2015 by the Department of Energy (DOE) and Idaho National Laboratory (INL). Its purpose is to coordinate DOE resources and expertise and focus them on solving issues in modern nuclear code validation and knowledge management. In time, code owners, users, and developers will view $\mathrm{NEKVaC}$ as an essential resource for acquiring the best practices and latest techniques for validating codes, providing guidance in planning and executing experiments, facilitating access to and maximizing the usefulness of existing data, and preserving knowledge for continual use by nuclear professionals and organizations for their own validation needs.

Three objectives comprise the principal mission of NEKVaC, which is to: (1) identify and prioritize projects that extend the field of validation science and its application to modern codes, (2) develop and disseminate best practices and guidelines for high-fidelity multiphysics/multiscale analysis code development and associated experiment design, and (3) define protocols for data acquisition and knowledge preservation and provide a portal for access to databases currently scattered among numerous organizations.

This report summarizes the planning activities that were conducted in FY-16. The activities described herein not only as have high potential for near-term success in demonstrating NEKVaC objectives, but also for resolving some of the issues in task execution, providing communication between functional elements to avoid "stove-piping," and raising awareness of NEKVaC and its mission. Lessons learned in conducting these tasks will help to effectively grow the program and optimize the use of DOE resources.
\end{abstract}




\section{CONTENTS}

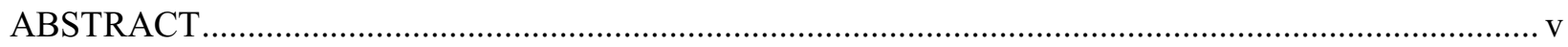

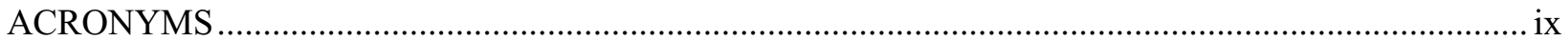

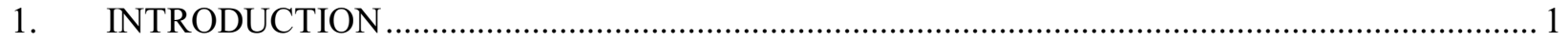

2. FISCAL YEAR 2016 ACTIVITIES AND NEAR-TERM PLANS …...................................... 1

2.1 Multiphysics Validation Support of Nuclear Energy Programs ............................................. 1

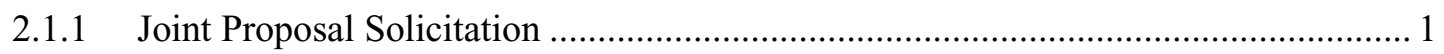

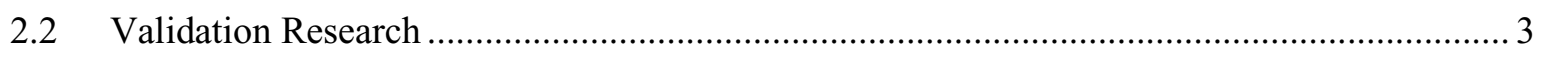

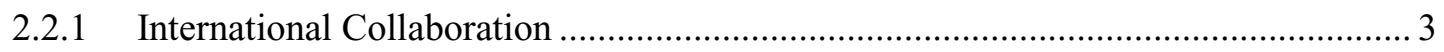

2.2.2 Advanced Data Superposition Using Vintage Data to Validate Modern Numerical Models_-Legacy Data Research Project................................................. 3

2.3 Knowledge Management and Retention ......................................................................... 4

2.3.1 Nuclear Data Access and Recovery ....................................................................... 4

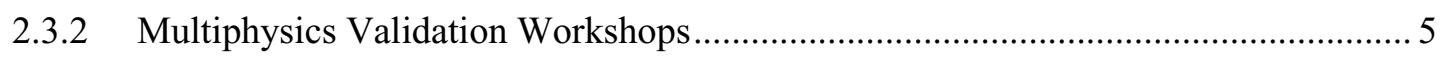

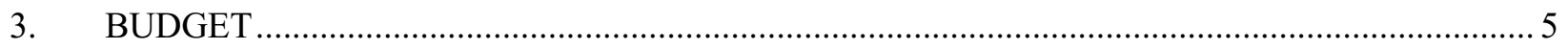

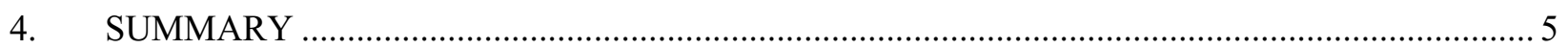

Appendix A - NEKVaC Workshop on Verification and Validation of Nuclear Engineering

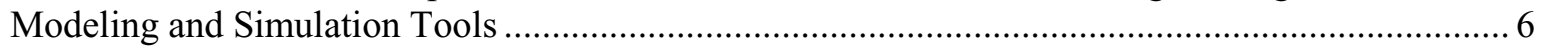

Appendix B - Proposal to Construct a Transient Fuel Validation Database using Legacy TREAT data and based upon the NEKAMS model ...................................................................................... 8

\section{TABLE}

Table 1. Validation and knowledge management proposals submitted to NEKVaC in FY-15 and FY-16. 2

Table 2: Simplified budget for FY-16 project activities. 5 


\section{ACRONYMS}

ANL Argonne National Laboratory

ANS American Nuclear Society

ART Advanced Reactor Technologies

CASL Consortium for Advanced Simulation of Light Water Reactors

CCTF Cylindrical Core Test Facility

DOE Department of Energy

EBR-II Experimental Breeder Reactor-II

EGMPEBV Expert Group in Multi-physics Experimental Data, Benchmarks, and Validation

FY fiscal year

ICSBEP International Criticality Safety Benchmark Evaluation Project

INL Idaho National Laboratory

IRPhEP International Reactor Physics Experiment Evaluation Project

LBLOCA large break loss-of-coolant accident

LOFT loss of fluid test

LWRS Light Water Reactor Sustainability

NEAMS Nuclear Energy Advanced Modeling and Simulation

NEKVaC Nuclear Energy Knowledge and Validation Center

OECD-NEA Nuclear Energy Agency of the Organization for Economic Cooperation and Development

ORNL Oak Ridge National Laboratory

PI principal investigator

PWR pressurized water reactor

SCTF Slab Core Test Facility 


\section{The Nuclear Energy Knowledge and Validation Center Summary of Activities Conducted in Fiscal Year 2016}

\section{INTRODUCTION}

The Nuclear Energy Knowledge and Validation Center $(\mathrm{NEKVaC})$ is a new initiative created by the Department of Energy (DOE) and Idaho National Laboratory (INL). Its goal is to coordinate DOE resources and expertise and focus them on solving issues in modern nuclear code validation and knowledge management. Once it is well-established, code owners, users, and developers will view $\mathrm{NEKVaC}$ as a useful partner. It will serve as an essential resource for acquiring the best practices and latest techniques for validating codes, providing guidance in planning and executing experiments, facilitating access to and maximizing the usefulness of existing data, and preserving knowledge for continual use by nuclear professionals and organizations for their own validation needs.

The scope of NEKVaC covers many interrelated activities that will need to be cultivated carefully in the near-term and managed properly once $\mathrm{NEKVaC}$ is fully functional. The principal mission is comprised of three objectives, which are to: (1) identify and prioritize projects that extend the field of validation science and its application to modern codes, (2) develop and disseminate best practices and guidelines for high-fidelity multiphysics/multiscale analysis code development and associated experiment design, and (3) define protocols for data acquisition and knowledge preservation and provide a portal for access to databases currently scattered among numerous organizations. While each mission objective has a unique focus, they are interdependent and complementary. Likewise, all activities supported by $\mathrm{NEKVaC}$, both near-term and long-term, must possess elements supporting all three objectives. This cross-cutting nature is essential to ensuring that activities and supporting personnel do not become "stove-piped" (i.e., so focused on a specific function that the activity itself becomes the objective rather than achieving the larger vision).

This report begins with a description of the mission objectives; specifically, it defines the role played by each major committee and the types of activities for which they are responsible. It then lists and describes the proposed near-term tasks upon which future efforts can build.

\section{FISCAL YEAR 2016 ACTIVITIES AND NEAR-TERM PLANS}

\subsection{Multiphysics Validation Support of Nuclear Energy Programs}

The Nuclear Energy Advanced Modeling and Simulation (NEAMS), Consortium for Advanced Simulation of Light Water Reactor (CASL), Advanced Reactor Technologies (ART), and Light Water Reactor Sustainability (LWRS) programs have successfully demonstrated the power of their tools to simulate complex behavior. The NEAMS Toolkit includes a wide range of nuclear fuel, material, radiation transport, fluid, and structural dynamics. Understandably, the early years of the program emphasized the development and integration of the codes into the toolkit. As the tools are applied to more practical problems (with a forward-looking focus on predictability and licensing support), the need to validate these complex models becomes more obvious. NEKVaC personnel have ongoing discussions with the National Technical Directors (NTDs) about these programs to identify and plan validation projects.

\subsubsection{Joint Proposal Solicitation}

In FY-16, proposals for multiphysics validation projects were solicited from the NTDs. Selected projects were to be jointly funded by the programs and by $\mathrm{NEKVaC}$, given suitable funding. Pre-proposals, using the INL's Laboratory Directed Research and Development format, were submitted and added to the set of proposals received in FY-15. These are listed in Table 1. 
Table 1. Validation and knowledge management proposals submitted to NEKVaC in FY-15 and FY-16.

\begin{tabular}{|c|c|c|}
\hline Project & Lead Institution/PI & $\begin{array}{r}\text { NE Program } \\
\text { (or Company) }\end{array}$ \\
\hline $\begin{array}{l}\text { Sustained Excellence of IRPhEP/ICSBEP with Integration } \\
\text { of Expertise into NEKVaC }\end{array}$ & INL (Bess) & $\begin{array}{l}\text { NEET } \\
\text { (International } \\
\text { Benchmarks) }\end{array}$ \\
\hline $\begin{array}{l}\text { Knowledgebase architecture and functionality development } \\
\text { for single- and two-phase/boiling flow experiment data } \\
\text { management to support calibration and validation of } \\
\text { high-fidelity modeling and simulation codes }\end{array}$ & $\begin{array}{l}\text { Oak Ridge National } \\
\text { Laboratory } \\
\text { (ORNL) (Ren) }\end{array}$ & CASL/LWRS \\
\hline THORS Data Recovery & ORNL(Carbajo) & ART \\
\hline $\begin{array}{l}\text { EBR-II Shutdown Heat Removal Testing Program } \\
\text { Benchmark }\end{array}$ & $\begin{array}{l}\text { Argonne National } \\
\text { Laboratory (ANL) } \\
\text { (Sumner) }\end{array}$ & ART \\
\hline Modern validation practice of reactor safety analysis codes & ANL $(\mathrm{Hu})$ & Multiple \\
\hline $\begin{array}{l}\text { Archival and Evaluation of LMR Thermal-Hydraulics } \\
\text { Validation Data through SESAME Collaboration }\end{array}$ & ANL (Thomas) & ART \\
\hline $\begin{array}{l}\text { Development of a database of TREAT metal fuel } \\
\text { experiments for the validation of SFR severe accident } \\
\text { analysis codes focused on transient overpower (TOP) and } \\
\text { loss-of-flow (LOF) accidents }\end{array}$ & ANL (Tentner) & FCRD \\
\hline $\begin{array}{l}\text { Development of a Fast Reactor Validation Database } \\
\text { System Using ZPR-9/32 and ZPPR-12 Reactor Physics } \\
\text { Data }\end{array}$ & ANL (Lell) & ART \\
\hline Modern Benchmark Case for Historic RIA Experiments & INL (Wachs) & FCRD \\
\hline $\begin{array}{l}\text { Development of Standardized Requirement Traceability } \\
\text { Matrix (RTM) for Next Generation Nuclear System } \\
\text { Simulation Tools Validation }\end{array}$ & INL (Choi) & LWRS \\
\hline $\begin{array}{l}\text { Integral Effects Tests and Associated Validation and } \\
\text { Benchmarking of RISMC Modeling and Simulation Tools }\end{array}$ & INL (Gaertner) & LWRS/CASL \\
\hline $\begin{array}{l}\text { Development and Assessment of Multiscale Simulation } \\
\text { Methods for Containment Thermal-Hydraulics Risk- } \\
\text { Informed Analysis }\end{array}$ & INL (Youngblood) & LWRS \\
\hline $\begin{array}{l}\text { Implementation of Dynamical System Scaling Procedures } \\
\text { for an Advanced Quantifiable and Traceable Evaluation } \\
\text { Model Assessment Process }\end{array}$ & INL (Zou) & Nuscale \\
\hline $\begin{array}{l}\text { Numerical Validation of Single-Phase Natural Circulation } \\
\text { Phenomena with RISMC Tools }\end{array}$ & INL (Zou) & LWRS \\
\hline
\end{tabular}

Once sustainable funds for NEKVaC are established, a review committee will review these preproposals. Full proposals for the most promising will be solicited, reviewed, and prioritized. 


\subsection{Validation Research}

\subsubsection{International Collaboration}

The Nuclear Energy Agency of the Organization for Economic Cooperation and Development (OECD-NEA) Expert Group on Multi-physics Experimental Data, Benchmarks, and Validation (EGMPEBV) was created in 2012 and 2013 to address, through an international collaboration, various challenges in the validation of modern nuclear simulations. U.S. representatives to the EGMPEBV included Phillip Finck and Tim Valentine (ORNL), Kumar Rohatgi (Brookhaven National Laboratory), and Kostadin Ivanov (Penn State, now at NC State). A member country would set up its own national "Nuclear Validation Center" to focus on parochial needs and interests, but it would share best practices and data through participation in EGMPEBV-planned activities. NEKVaC was set up in late 2014 as the U.S. validation center.

In FY-17, NEKVaC will provide financial support to additional center staff to attend the EGMPEBV meetings and participate in joint activities.

\subsubsection{Advanced Data Superposition Using Vintage Data to Validate Modern Numerical Models-Legacy Data Research Project}

In FY-16, NEKVaC sponsored one research project related to the retrieval, requalification, and analysis of legacy data for modern thermal fluid model validation. It was approved in FY-15, but did not actually begin in earnest until early FY-16, as the principal investigator (PI) had some difficulty in finding a qualified student to help with the research. The project, entitled "Advanced Data Superposition," is now proceeding at pace and should conclude in FY-17.

Over the years, an enormous quantity of data has been recorded for validating numerical models written to analyze the thermal-hydraulic behavior of light water reactors. These data, not including data specifically gathered to study the thermal-hydraulic behavior of Russian reactor designs, may be divided into three large groups based on vendor designs specific to: (1) boiling water reactors (General Electric), (2) French/Westinghouse ${ }^{a}$-type pressurized water reactors, and (3) Babcock \& Wilcox pressurized water reactors (PWR). Because the experiments (which were designed to address potential issues, to study specific phenomena, and to study the interactions between multiple phenomena within each of these three groups) share common geometries and boundary conditions, it may be possible to use an ensemble of data sets from related experiments, even from different experimental facilities. This would produce a more comprehensive picture of fluid/heat transfer behavior than would be possible when considering only individual experiments.

This approach, termed advanced data superposition, proceeds by first normalizing data sets from different (but related) experiments using scaling laws. Second, the subject data are presented in a framework defined by one of the group experiments, which is designated as the "baseline" or "reference" experiment. Thus, the scaled data in the ensemble, related by a common issue or set of phenomena and the same variable range, are used as a whole. These data are superimposed on the existing data of the most rigorous experiment of the ensemble to show detailed behavior (for example, both one-dimensional [1-D] and three-dimensional [3-D]). In this way, a data set that better meets the validation needs of the modern, sophisticated numerical models than the existing vintage data repertoire is made available.

a Including also Combustion Engineering designs. 
For this project, the 3-D data recorded in the cylindrical core test facility (CCTF) and the slab core test facility (SCTF) are being superimposed on the reflood phase of the loss of fluid test (LOFT) large break loss-of-coolant accident (LBLOCA) data. The LOFT data is the "reference" experiment; it is an integral experiment that provides 1-D data covering an entire LBLOCA experiment, while the CCTF and SCTF experiments provide 3-D data specific only to the reflood phase of the LBLOCA. The LOFT, CCTF, and SCTF facilities were all designed to study the behavior of LBLOCA phenomena for a Westinghouse-type PWR.

Within the context of the above hypothesis, three tasks are underway:

1. Theoretical development of an advanced data superposition approach

2. Division of validation data from multiple experiments within Groups 1 and 2 into candidates for advanced data superposition to create more comprehensive data sets

3. Application of advanced data superposition to related validation data sets.

A more traditional fourth task may be conducted:

4. Based on validation needs specific to advanced numerical tools presently under development, data sets available in the global community will be identified, and the relationship between the data and the desired validation need will be defined and documented.

By the summer of 2016, data available for the refill and reflood phases of a PWR LBLOCA were acquired and reviewed. In addition, candidate small break loss-of-coolant accident (SBLOCA) experiments and facilities are under review.

The PI on this project is Dr. Richard Schultz, who has retired from INL and is now a professor at Idaho State University. Dr. Schultz is a renowned expert in fluid flow and thermal-hydraulic code validation. He has worked on the LOFT, the Westinghouse AP600 Integral Experiment Advanced Plant Experiment, and, most recently, the Next Generation Nuclear Plant project, in which he designed the validation experiment matrix. This project is expected to be completed in FY-17.

\subsection{Knowledge Management and Retention}

\subsubsection{Nuclear Data Access and Recovery}

Large amounts of fuel, material, and thermal fluid data suitable for model validation exist but are widely distributed among different organizations such as the Nuclear Regulatory Commission, OECD-NEA, the Office of Science and Technology Information, and numerous academic institutions where experiments have been performed. A one-stop "portal" to existing databases would be an invaluable resource for modelers. The need for this portal creates a high and near-term priority for a new knowledge management capability to be developed under NEKVaC. Based upon the Nuclear Energy Knowledge Base for Advanced Modeling and Simulation model, data not currently stored in a central database can be acquired and stored in a secure data repository hosted by ORNL. The NEKVaC portal will point to data already in established public databases. The development of the NEKVaC knowledge management system is outlined in "Nuclear Energy Knowledgebase and Simulation Code Validation System Development and Implementation Plan" (ORNL/TM-2015/420), which was prepared for NEKVaC in FY-15.

Initial planning of a project for pilot transient fuel test data recovery and benchmarking took place in FY-16. The preliminary plan calls for the development of two transient fuel performance benchmark cases. This development will use legacy data to be recovered from TREAT experiment files. The first benchmark will be based upon a TREAT experiment performed on a fast reactor fuel pin. The data are already being collected for this by a team at Oregon State University under a DOE Integrated Research Project (entitled "Computational and Experimental Benchmarking for Transient Fuel," with Wade Marcum serving as the PI). 
The second benchmark will be based upon a test series conducted at the Special Power Excursion Reactor Test facility on stainless-steel-clad $\mathrm{UO}_{2}$ fuel pins. Tests on stainless-steel-clad fuel are not as widely available as tests on fuel with zircaloy cladding. Collectively, they can serve as a good starting point for evaluating concepts related to FeCrAl-clad fuel that are being developed for the Accident Tolerant Fuel program. The goal will be to identify all the relevant data streams (relevance being defined by a stakeholder set that includes the modeling and simulation community, regulatory community, and fuel design community). Those would best be identified by people who actively consume such information.

Development of a standard database structure (leading to the construction of, or inclusion in, an actual database) would be developed to capture and communicate that information. A proposal for such an activity was solicited from ORNL and is included in the Appendix B. With new FY-17 funding, this pilot project will start in FY-17.

\subsubsection{Multiphysics Validation Workshops}

A workshop on multiphysics validation has been developed with support from NEKVaC. The workshop, developed at North Carolina State University, has been conducted at U.S. universities and at overseas venues. In FY-17, NEKVaC will continue to develop and present this workshop. The workshop description and agenda is provided in Appendix A.

\section{BUDGET}

Activity levels in FY-17 will be modest, as the effort is being funded solely by FY-16 carryover funds of $\sim \$ 130 \mathrm{~K}$. Table 2 shows a simplified breakdown of the budget for FY-16 activities.

Table 2: Simplified budget for FY-16 project activities.

\begin{tabular}{|l|l|}
\hline Amount (\$) & Activity \\
\hline $70 \mathrm{~K}$ & $\begin{array}{l}\text { Advanced Data Superposition research project } \\
\text { completion }\end{array}$ \\
\hline $15 \mathrm{~K}$ & Multiphysics Validation Workshop \\
\hline $20 \mathrm{~K}$ & ORNL data stream/portal construction \\
\hline $25 \mathrm{~K}$ & Project Planning and Travel \\
\hline
\end{tabular}

The Transient Fuel Data Recovery and Benchmark Pilot Project is estimated to cost around \$200K. Costs will be covered by new FY-17 funding if it materializes. Funding of one or more joint projects in validation will be pursued as new FY-17 funding allows.

\section{SUMMARY}

This report described the activities sponsored by the Nuclear Energy Knowledge and Validation Center in FY-16 in the context of its mission areas: support of multiphysics validation efforts within DOE programs, validation research, and knowledge management.

Specific FY-16 activities included:

- Continuation of the Advanced Data Superposition research project with Idaho State University

- Solicitation of proposals for jointly funded validation research

- Initial planning of a pilot data recovery/benchmark with legacy transient fuel test data

- Development of a Multiphysics Validation Workshop

- Support of the OECD-NEA EGMPEBV. 


\section{Appendix A - NEKVaC Workshop on Verification and Validation of Nuclear Engineering Modeling and Simulation Tools}

\section{Synopsis:}

Advances in scientific computing have made modeling and simulation an important part of nuclear engineering and science. This workshop will provide participants with an understanding of comprehensive and systematic development of concepts, principles, and procedures for verification and validation of nuclear engineering models and simulations. These will include reactor physics, core and system thermal hydraulics, and fuel modeling, as well as traditional and novel multi-physics modeling and simulation. The major focus of the workshop will be validation principles, including the use of predictive capability maturity modeling as applied to nuclear engineering tools and their applications.

\section{Targeted Audience:}

Young professionals from industry, regulation, national laboratories, and government agencies, as well as graduate students and post-doctoral scholars from universities

Length and Location of the Workshop: One week at North Carolina State University (NCSU)

Lecturers: Professors Kostadin Ivanov, Maria Avramova, and Nam Dinh from NCSU

Cost Estimate: $\$ 15,000$

Agenda and Syllabus:

1. Monday

Introduction to the workshop

Definitions, concepts, and terminology

a. Primary terms and concepts

b. Modeling and computer simulation

c. Software engineering and quality assurance

d. Types and sources of uncertainties in modeling

e. Introduction to sensitivity analysis

f. Classification of methods for assessment and propagation of uncertainties

g. Predictive Capability Maturity Modeling (PCMM) in code development and applications

2. Tuesday

Code verification
a. Criteria and order of accuracy
b. Systematic mesh refinement
c. Exact solutions
d. Benchmarks and inter-code comparisons

3. Wednesday

Solution verification 

a. Round-off and iterative errors
b. Statistical sampling error
c. Truncation and discretization errors
d. Solution adaptivity

4. Thursday

Model validation
a. Fundamentals
b. Design and utilization of validation experiments
c. Model accuracy assessment
d. Predictive capability

5. Friday

Applications on validation

a. Validation of single-physics, single-scale models

b. Validation of single-physics, multi-scale models

c. Validation of multi-physics, single-scale models

d. Validation of multi-physics, multi-scale models

e. Validation benchmarks

The theory lectures and assignments will be complemented with demonstration computer exercises and examples. Reports will be generated to include feedback from participants. 


\section{Appendix B - Proposal to Construct a Transient Fuel Validation Database using Legacy TREAT data and based upon the NEKAMS model}

To prepare for technical development of computational code validation under the Nuclear Energy Knowledge and Validation Center (NEKVAC) initiative, several meetings were held by a group of experts of the Idaho National Laboratory (INL) and the Oak Ridge National Laboratory (ORNL) to develop requirements of, and formulate a structure for, a transient fuel database through leveraging existing resources. It was concluded in discussions of these meetings that a pilot project is needed to address the most fundamental issues that can generate immediate stimulus to near-future validation developments as well as long-lasting benefits to NEKVAC operation. The present project is proposed based on the consensus of these discussions.

Analysis of common scenarios in code validation indicates that the incapability of acquiring satisfactory validation data is often a showstopper that must first be tackled before any confident validation developments can be carried out. Validation data are usually found scattered in different places most likely with interrelationships among the data not well documented, incomplete with information for some parameters missing, nonexistent, or unrealistic to experimentally generate. Furthermore, with very different technical backgrounds, the modeler, the experimentalist, and the knowledgebase developer that must be involved in validation data development often cannot communicate effectively without a data package template that is representative of the information domain of interest to the desired code validation.

This pilot project is proposed to use the legacy TREAT Experiments Database to provide core elements for a desired validation data package. Data gaps and missing data interrelationships will be identified from these core elements. All the identified missing elements will then be filled in with experimental data if available from other existing sources or with surrogate data if nonexistent. The resulting hybrid validation data package (composed of experimental and surrogate data) will provide a clear and complete instance delineating the structure of the desired validation data and enabling effective communication among the modeler, the experimentalist, and the knowledgebase developer. With a good common understanding of the desired data structure by the three parties of subject matter experts, further existing data hunting will be effectively conducted, new experimental data generation will be realistically pursued, knowledgebase schema will be practically designed; and code validation will be confidently planned.

The hybrid data package will first be uploaded into the Nuclear Energy-Knowledgebase for Advanced Modeling and Simulation (NE-KAMS) along with some expansion of the NE-KAMS structure as needed to establish a common base for communications among the three parties of subject matter experts. The uploaded hybrid data package will also provide a map for creating a complete validation data package of experimental data, and further, facilitate networking scattered existing datasets preserved in different sources for the complete package. The network will allow new experimental data to be generated and preserved in databases at different locations, e.g. NDMAS at INL or VELO at PNNL, for cost- and time efficiency. Meanwhile, a duplicate will be uploaded into NE-KAMS for backup and enhanced accessibility. 
This pilot project will establish requirements for a networked transient fuel database, formulate the structure of transient fuel information domain, deliver a tangible framework along with operation protocols for transient fuel validation data accumulation and management, provide a visual instance of a complete validation data package to facilitate future experimental data generation and validation development planning, and retain unique expertise required for long-term NEKVAK development and operation.

Due to unclear prospective funding situation at this point, a budget for the proposed pilot efforts is not made. However, the tasks are defined to allow piecewise developments that would fit into available funds. 